\title{
Preface
}

\section{New Year, New Opportunity and New Commitment}

\author{
Yi-Fei Wang, Dan-Qing Ren, Qin-Zhu Zheng, Hui Zhang \\ Editorial Office, Asian Journal of Andrology, 294 Tai-yuan Rd, Shanghai 200031, China \\ Asian Journal of Andrology (2009) 11: 5. doi: 10.1038/aja.2008.55.
}

A new year is with us again. The Year of 2009 is starting.

Above all, we hope that the Year of 2009 will bring to all of you and your families best wishes, as well as a happy and harmonious New Year.

Bathed in the first beam of sunlight in the New Year, we are greatly pleased to present this special issue on Prostate Cancer with great works of Prof. Roger S. Kirby (Editor-inChief, Prostate Cancer and Prostatic Diseases; Director, The Prostate Centre, London, UK) and Prof. Shu-Jie Xia (Editorial member of Asian Journal of Andrology (AJA); Director, Department of Urology, Shanghai First People's Hospital, Shanghai Jiao Tong University, Shanghai, China) as well as outstanding contributions of all authors. We sincerely hope that you would enjoy the novel perspectives and insights that the articles in this special issue

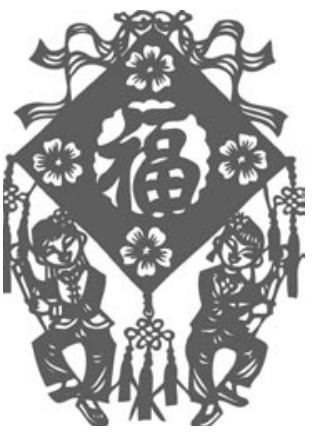
would convey, and in the meantime enjoy the beautiful cover. It is certain to be an auspicious start for AJA in the New Year.

Traditionally, this is the season for looking back at the experience from the past and looking ahead to the new hopes for the future.

Looking back at the year of 2008 that has left us, we indeed have some satisfying gains to deliver: we published two special issues with interesting topics (Men's Health \& Erectile Dysfunction; Hormones and Sports: 2008 Olympics Special Section) and good feedbacks; we had new cooperation agreement with internationally well-known Nature Publication Group (NPG); and we made great strides in the preparation for the Third Asia-Pacific Forum on Andrology (3APFA), in conjunction with the Tenth Anniversary Celebration of Asian Journal of Andrology (AJA) which will take place on October 10-13, 2009, Nanjing, China.

Looking ahead to the year of 2009, we realize that, to us, the New Year is full of opportunities and challenges. Move forward, we will work to further entrench the position of AJA as an internationally well-known andrological journal and to strive for opportunities and contributions in much broader fields for sustaining our competitiveness in the future.

The year of 2009 is the lunar year of Ox, implying diligence and power. Therefore we enter 2009 with greater determination, devotion and dedication.

The New Year is also the time of saying thanks. We are highly grateful for strong supports from all advisory and editorial board members, reviewers, authors, readers and all persons of help to us. In the New Year, we are looking forward to your persistent, consistent, continuing and increasing support to our efforts in strengthening AJA.

The year 2009 is stretching her arms to embrace you into a new, refreshing and prosperous world. Once again, we sincerely wish that you're on the way towards your goals and the fulfillments of your resolutions. We also hope AJA will continue to make significant strides on the way to its aspiration and pursuit.

2009 is upon us - enjoy!

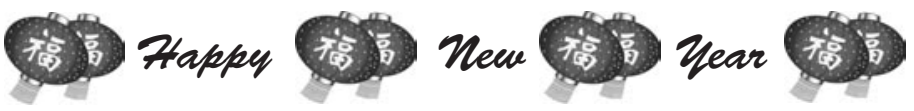

